OPEN ACCESS

Edited by:

Thimios Mitsiadis,

University of Zurich, Switzerland

Reviewed by:

Pierfrancesco Pagella,

University of Zurich, Switzerland

Claudio Cantù,

Linköping University, Sweden

*Correspondence:

Susan Wray

wrays@ninds.nih.gov

Specialty section:

This article was submitted to

Stem Cell Research,

a section of the journal

Frontiers in Cell and Developmental

Biology

Received: 23 September 2019 Accepted: 15 January 2020

Published: 30 January 2020

Citation:

Shan Y, Saadi H and Wray S (2020) Heterogeneous Origin

of Gonadotropin Releasing Hormone-1 Neurons in Mouse Embryos Detected by Islet-1/2

Expression

Front. Cell Dev. Biol. 8:35. doi: 10.3389/fcell.2020.00035

\section{Heterogeneous Origin of} Gonadotropin Releasing Hormone-1 Neurons in Mouse Embryos Detected by Islet-1/2 Expression

\author{
Yufei Shan, Hassan Saadi and Susan Wray* \\ Cellular and Developmental Neurobiology Section, National Institute of Neurological Disorders and Stroke, National Institutes
} of Health, Bethesda, MD, United States

In vertebrates, Gonadotropin releasing hormone-1 $(\mathrm{GnRH})$ neuroendocrine cells originate in the olfactory placode and migrate into the forebrain where they regulate reproduction. However, the embryonic lineage of their progenitors remains controversial. Most GnRH neurons are derived from placodal ectodermal progenitor cells, but data from lineage tracing in zebrafish (Whitlock et al., 2003) and mouse (Forni and Wray, 2012) indicate that some GnRH progenitor cells have a neural crest (NC) origin. In contrast, a recent study in zebrafish (Aguillon et al., 2018), using Islet1/2 expression, identified this LIM-homeodomain protein in all developing $\mathrm{GnRH}$ neuroendocrine cells, and the authors concluded a homogenous origin from progenitors within the preplacodal ectoderm. Evidence in different animal models and systems suggests that expression of Islet-1 plays a pivotal role in cell fate specification and differentiation. Thus, expression of Islet-1/2 in all GnRH cells in the nasal placode may not be lineage dependent but rather initiated locally in the placode as part of the program for $\mathrm{GnRH}$ cell specification and/or differentiation. This study addresses this issue and shows two populations of olfactory derived $\mathrm{GnRH}$ neurons in embryonic mouse: Islet$1 / 2(+)$ and Islet-1/2(-). Notably, triple-label immunofluorescence using the NC lineage tracer Wnt1, showed that GnRH neurons derived from Wnt1 progenitors are Islet-1/2(-). These results are consistent with two separate origins of $\mathrm{GnRH}$ neuroendocrine cells and suggest that either (1) NC-derived GnRH cells differentiate earlier than PE-derived $\mathrm{GnRH}$ cells or (2) different programs are used for cell specification in NC- vs. PE-derived GnRH cells.

Keywords: neural crest, Islet-1/2, GnRH, neurodevelopment, olfactory development, lineage tracing

\section{INTRODUCTION}

How pluripotent progenitors give rise to different neuronal subtypes during development is a fundamental biological question. Nasal placodes invaginate to form the olfactory epithelium and vomeronasal organ and give rise to multiple cell types including olfactory sensory neurons, pheromone receptor neurons, olfactory ensheathing cells, sustentacular cells and the neuroendocrine gonadotropin releasing hormone-1 (GnRH) cells. The GnRH cells leave the 
olfactory pit and migrate along olfactory axons to the base of the developing olfactory bulbs during early embryonic development (Schwanzel-Fukuda and Pfaff, 1989; Wray et al., 1989b). After reaching the nasal forebrain junction (NFJ), the main and accessory olfactory axons target the olfactory bulb, GnRH neurons migrate along a subset of axons which turn caudally and enter the developing forebrain (Wray, 2010). Once within the forebrain, GnRH cells become integral components of the hypothalamic-pituitary-gonadal axis, regulating sexual maturation and reproduction in vertebrates (Constantin, 2011). Disruption of GnRH neuronal development and olfactory axon targeting is seen in patients with Kallmann Syndrome (Kallmann et al., 1944).

Nasal placodes were initially defined as ectodermally derived tissue thickenings that arise from the anterior end of the neural plate, but work in zebrafish and mouse indicate that these placodes are comprised of both placodal ectoderm cells and neural crest (NC) cells (Barraud et al., 2010; Forni et al., 2011; Katoh et al., 2011). From E9.5 to E10.5 in mice, Wnt1-Cre recombination (NC lineage tracer) was found in a subset of cells distributed along the invaginating olfactory pit and the ectoderm lining the nasal placode. From E11 to E11.5, the number of cells positive for Wnt1Cre-mediated recombination increased in the respiratory epithelium, vomeronasal organ, and olfactory epithelium (Forni et al., 2011). The literature agrees, based on lineage tracing studies, that the majority of nonsensory respiratory epithelium, olfactory sensory neurons and other support cells, originate from ectodermal progenitors, and that NC cells migrating into the olfactory placode give rise to olfactory ensheathing cells (Barraud et al., 2010; Forni et al., 2011; Katoh et al., 2011).

Forni et al. (2011), also reported that although the majority of GnRH cells were derived from placodal ectoderm progenitors, a subpopulation of $\mathrm{GnRH}$ cells and olfactory sensory neurons arise from NC progenitors. At E11.5, the first GnRH-expressing cells can be immunodetected in the ventromedial portion of the developing vomeronasal organ and double immunostaining of Wnt1Cre/RLacZ or Wnt1Cre/RYFP mice at this age, highlighted Wnt1Cre recombination in some $\mathrm{GnRH}$ neurons in nasal regions. In zebrafish, two studies indicated that the neuroendocrine GnRH neurons (called GnRH3, Abraham et al., 2010) associated with the developing olfactory epithelium are derived from two separate regions: the adenohypophyseal region (Whitlock et al., 2003), and the cranial NC progenitor pool of the neural plate (Whitlock et al., 2003; Onuma et al., 2011). Although the $\mathrm{GnRH}$ neuroendocrine population does not receive a contribution from the adenohypophyseal region in mouse (Metz and Wray, 2010), a dual lineage is consistent with ectoderm and NC contributions. A recent study in zebrafish (Aguillon et al., 2018), however, concluded that all zebrafish GnRH3 neurons have a homogenous origin from ectodermal progenitors based on co-labeling with an antibody that recognized Islet- $1 / 2$.

Islet-1 and Islet-2 are paralogous LIM-homeodomain transcription factors. Mice in which Islet-1 or Islet-2 genes have been individually disrupted are each lethal, but the phenotypes differ, showing that the paralogs are not genetically redundant. $I s l 1^{-/-}$mice die around embryonic day 11.5 with abnormal heart and pancreas development and an absence of motor neurons (Pfaff et al., 1996), whereas $I s l 2^{-/-}$mice die just after birth, due to defects in motor neuron differentiation in the thoracic levels of the spinal cord altering breathing (Thaler et al., 2004). Examination of E11.5 sections for Islet-1 and Islet-2 in The Allen Brain Atlas shows robust labeling of Islet-1 in the developing placode while Islet-2 is primarily expressed in the nasal mesenchyme surrounding the invaginating placode, consistent with Islet-1 expression in placodally derived cells.

Islet-1 is expressed in many embryonic cells, and is an early marker of differentiation (Ericson et al., 1992). In chicken embryos, BrDU and Islet-1 double staining suggested that Islet$1(+)$ cells are postmitotic in the neural tube (Avivi and Goldstein, 1999). Islet- 1 is also expressed at the transition from neurogenesis to terminal differentiation in sensory neurons (Sun et al., 2008), motor neurons (Pfaff et al., 1996; Hobert and Westphal, 2000; Hutchinson and Eisen, 2006; Lee et al., 2015), cholinergic neurons in the telencephalon Elshatory and Gan (2008), striatonigral neurons (Lu et al., 2014), and mediobasal hypothalamic arcuate neurons (Lee et al., 2016). Thus, evidence in different animal models and systems suggests that expression of Islet-1 plays a pivotal role in cell fate specification and differentiation.

The present study addresses the expression of Islet-1/2 in lineage-derived GnRH cell subpopulations in the developing placode in mouse. This report shows that labeling for Islet-1/2 distinguishes two subpopulations of GnRH neurons in E11.5 and E12.5 embryonic mice. Although the majority of $\mathrm{GnRH}$ neurons were Islet-1/2(+) at both ages, a subpopulation of GnRH cells were Islet-1/2 negative. Consistent with $\mathrm{GnRH}$ neurons in mouse arising from two different sources of progenitor cells, the GnRH neuronal subpopulation lacking Islet-1/2, expressed the Wnt1 promoter-driven CRE recombination of Rosa-YFP. These results suggest that either (1) NC-derived GnRH cells differentiate earlier than PE-derived GnRH cells or (2) different programs are used for cell specification in NC- vs. PE-derived GnRH cells.

\section{MATERIALS AND METHODS}

\section{Animals}

All animal procedures were approved by Animal Care and Use Committee and performed in accordance with the National Institutes of Health, National Institute of Neurological Stroke and Disorders guidelines. Timed-mated NIH-Swiss pregnant mice were euthanized in a $\mathrm{CO}_{2}$ chamber, and embryos (E11.5 and E12.5) were collected. Collected embryos were immediately fixed in $4 \%$ paraformaldehyde/PBS $(1 \mathrm{~h})$, washed (PBS), cryoprotected in $30 \%$ sucrose/PBS $\left(4^{\circ} \mathrm{C}\right)$, embedded in Tissue Tek O.C.T. compound (Sakura Finetek), and frozen at $-80^{\circ} \mathrm{C}$ until cryosectioning. In a similar manner, E11.5 and E12.5 Wnt1-cre/Rosa-YFP mice (Forni et al., 2011) were obtained from time matings of Wnt1-cre mice crossed with Gt

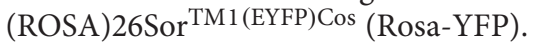

\section{Sectioning and Immunolabeling}

Fixed embryos were serial sectioned (10 $\mu \mathrm{m}$, Leica CM 3050S cryostat, Leica Biosystem). Two series were generated for E11.5 
embryos, 3 series for E12.5 embryos. Sections were kept at $-80^{\circ} \mathrm{C}$ until staining. Primary antibodies used were: Rabbit polyclonal anti-GnRH-1 (SW-1, 1:15000) (Wray et al., 1988), chicken anti-GnRH (1:100, Aves), mouse monoclonal anti-Islet1/2 [1:400, Developmental Studies Hybridoma Bank (DSHB)], rabbit polyclonal anti-Islet-1/2 (1:1000, Abcam), chicken antiperipherin (1:1000, Aves) and chicken anti-GFP (1:2000, Abcam). Both antibodies for Islet recognize Islet-1 and Islet-2. For both chromogen and fluorescence Islet-1/2 labeling, a 17-min microwave antigen retrieval treatment in citrate buffer was performed before blocking (Forni et al., 2006). Double and triple labeling were performed using primary antibodies generated in different species.

Embryonic sections were stained using methods previously described (Forni et al., 2011). Briefly, after a short fix (10 min) and PBS washes $(4 \times 5 \mathrm{~min})$, sections were blocked in $10 \%$ normal horse serum $/ 0.3 \%$ triton $\mathrm{X}-100$, washed with PBS and incubated in primary antibody overnight $\left(4^{\circ} \mathrm{C}\right)$. For chromogen double labeling, sections were washed, incubated $(1 \mathrm{~h})$ in a species appropriate biotinylated secondary antibody (donkey anti-mouse-bt, donkey anti-rabbit-bt (1:500 in PBS, Jackson ImmunoResearch), washed and processed with DAB (1st primary complex) followed by SG (2nd primary complex) (Kramer et al., 2000). For double and triple immunofluorescence labeling, sections were washed in PBS and incubated in a species appropriate secondary antibody. Fluorescent secondary antibodies used were: donkey anti-chicken-488 (1:1000, Invitrogen), donkey anti-rabbit-555 (1:1000, Invitrogen), donkey anti-mouse-555 (1:1000, Invitrogen), and strepavidin405 (1:1000, Invitrogen). After each secondary complex, sections were lightly fixed and washed prior to going into the next primary. After the final PBS wash, sections were counter stained with TrueBlack Lipofuscin Autofluorescence Quencher (Biotium Inc.) for $1 \mathrm{~min}$ to suppress red blood cells autofluorescence (Whittington and Wray, 2017), rinsed in $\mathrm{dH}_{2} \mathrm{O}$, then mounted using Vectashield hardset with DAPI (Vector Laboratories).

\section{Analysis}

7 NIH-Swiss mice (E11.5, $N=4$; E12.5, $N=3$ ), 6 Wnt1cre/Rosa-YFP mice (E11.5, $N=3$; E12.5; $N=3$ ) were examined. Chromogen stained sections were analyzed by two researchers, one counted directly from the microscope and the second counted from images obtained from a Nikon Eclipse E800 microscope with a Retiga SRV camera (QImaging) using iVision software (BioVision) and ImageJ (W Rasband, $\mathrm{NIH}$, Bethesda, MD, United States). The total number of GnRH cells and Islet-1/2(+) GnRH cells was quantified for each animal. Although timed-matings were performed, sizes of embryos and thus embryonic stage, can vary at these ages by 0.5 days. Thus, for each stage the percent of Islet-1/2 positive and negative cells are presented. The mean of the two researchers' values was used as a single value/animal. At E11.5, the developing pit is compact with GnRH cells confined to a relatively small region and at E12.5 $\mathrm{GnRH}$ cells are oftern cluster on migratory tracts. Thus, counting of double and triple labeled cells was done only when a

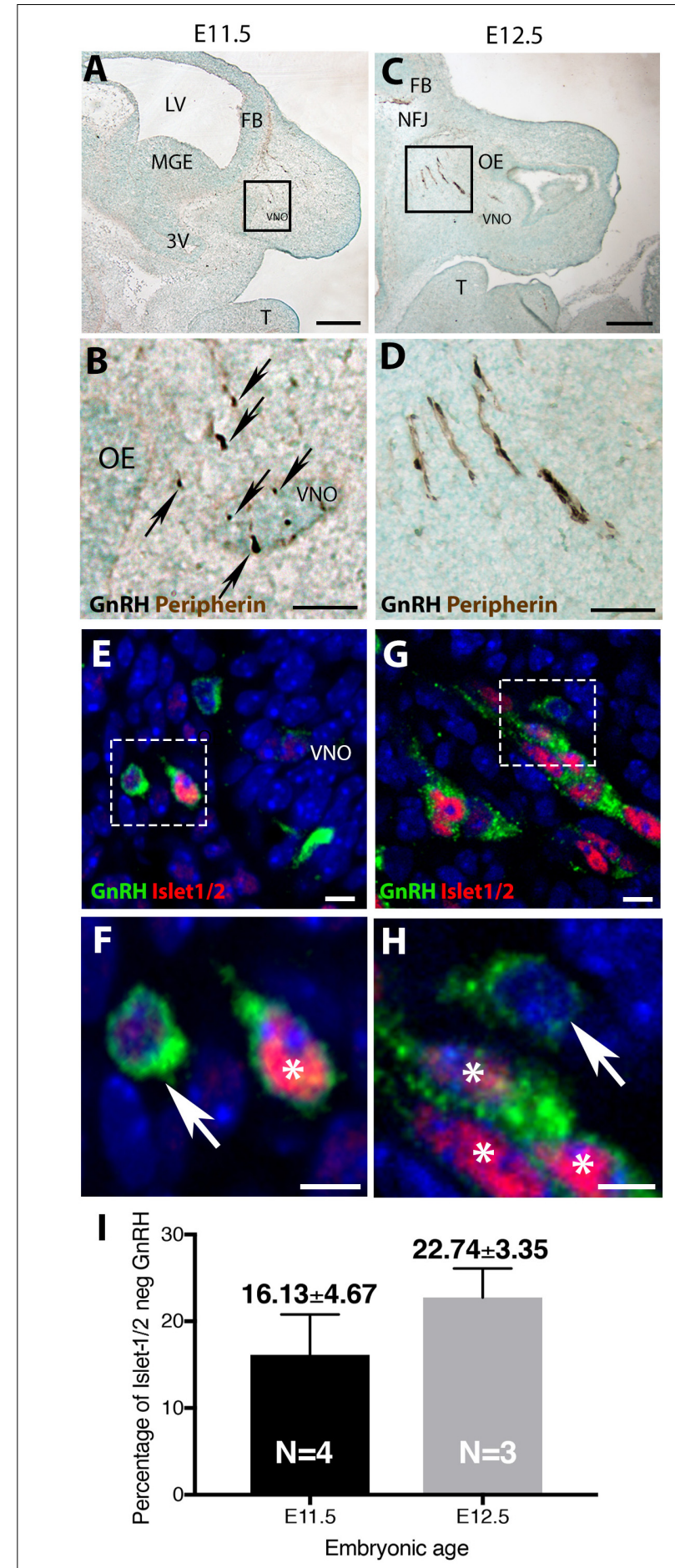

FIGURE 1 | Islet-1/2 expression delineates two populations of $\mathrm{GnRH}$ neurons. E11.5 (A,B) and E12.5 (C,D) stained parasagittal sections of nasal region. Low magnification $(\mathbf{A}, \mathbf{C})$ and higher magnification of boxed area $(\mathbf{B}, \mathbf{D})$ is shown. At E11.5 (A,B) GnRH neurons (blue-black cells, black arrows) within or adjacent to the VNO are detected. At E12.5 (C,D) GnRH neurons (blue-black) are detected migrating out of $\mathrm{VNO}$ along olfactory axons (brown) to the nasal-forebrain junction (NFJ). (E-H) Fluorescent expression of Islet-1/2 (red) in $\mathrm{GnRH}$ neurons (green). (E,F) At E11.5, GnRH neurons (green)/ Islet-1/2(+) (red, white asterisk) and GnRH neurons Islet-1/2(-) (white arrow)

(Continued) 
FIGURE 1 | Continued

were detected within or adjacent to the $\mathrm{VNO}$ (boxed area in $\mathbf{E}$ shown at higher magnification in F). (G,H) At E12.5, both Islet-1/2(+) (red, white asterisk) and Islet-1/2(-) (white arrow) GnRH cells (green) were detected along the migratory tracts (boxed area in $\mathbf{G}$ shown at higher magnification in $\mathbf{H}$ ). (I) Percentage of Islet-1/2 negative $\mathrm{GnRH}$ neurons at $\mathrm{E} 11.5$ and $\mathrm{E} 12.5, \mathrm{~N}=$ numbers of animals. FB, forebrain; OE, olfactory epithelium; VNO, vomeronasal organ; NFJ, nasal forebrain junction; LV, lateral ventricle; 3V, third ventricle; MGE, medial ganglionic eminence; T, tongue. Scale (A,C) $(250 \mu \mathrm{m}),(\mathbf{B}, \mathbf{D})(100 \mu \mathrm{m})$, (E-H) $(10 \mu \mathrm{m})$.

distinct nucleus of the cell was detected. For triple fluorescent labeling, images were taken at $60 \times$ on a Nikon TE200 spinning disk confocal microscope with a EMCCD imageM digital camera (Hamamatsu) using iVision software (BioVision) and ImageJ. GnRH cells were photographed at all three wavelengths and images examined, to determine if they were $\mathrm{YFP}(+)$ and/or Islet- $1 / 2(+)$.

\section{RESULTS}

In mice, at early embryonic ages, GnRH neurons are first detected in the olfactory pit/developing vomeronasal organ (VNO). At E11.5, most GnRH neurons are seen in the developing VNO, with a few GnRH neurons just outside of the VNO, starting their migration toward the forebrain (Figures 1A,B). At E12.5, most GnRH neurons are located on the migratory tracts in the nasal area (Figures 1C,D). Double labeling revealed that the majority of GnRH cells within the VNO (E11.5, Figures 1E,F) and on migratory tracts (E12.5, Figures $\mathbf{1 G}, \mathbf{H}$ ) co-expressed Islet-1/2 (Figures 1F,H, asterisk). However, at both ages, a subpopulation of GnRH cells were Islet-1/2(-) (Figures $\mathbf{1 F}, \mathbf{H}$, arrow). These Islet-1/2(-) GnRH cells did not have a unique location or morphology, but were intermingled with the Islet-1/2(+) GnRH cells, though were often found adjacent to each other on the migratory tracts. To determine the percentage of Islet-1/2(-) GnRH neurons, single- and double-labeled GnRH cells in serial sections (6-12 sections/ani-mal,10 $\mu \mathrm{m} /$ section) were counted.
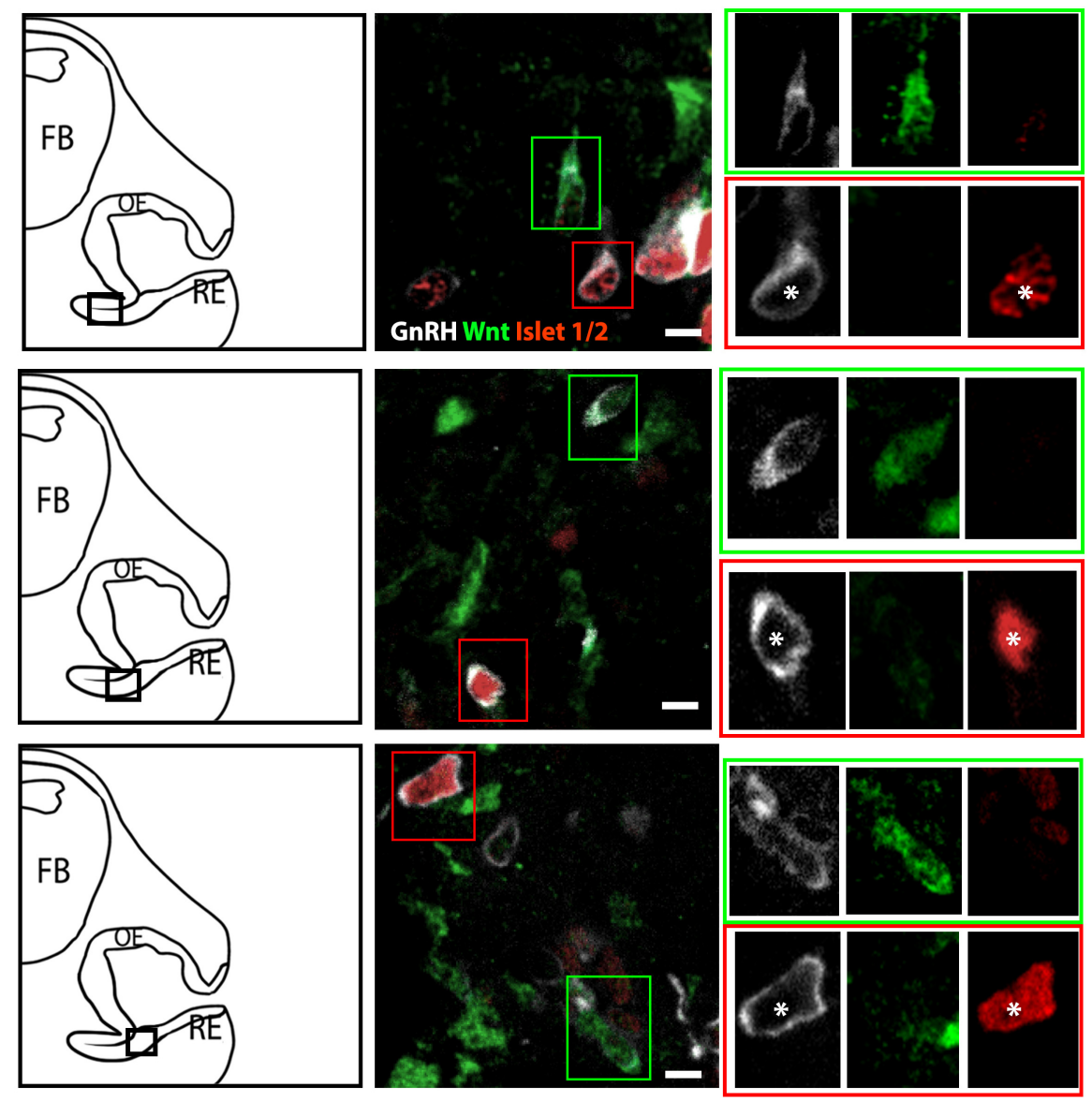

FIGURE 2 | Islet-1/2 staining identifies placodal ectodermally derived GnRH cells at E11.5. Representative sections of the VNO from 3 different E11.5 embryos stained for $\mathrm{GnRH}$, Wnt1-GFP and Islet-1/2. Left panels, schematics indicating VNO area from which the immunofluorescent images were taken (asterisk, boxed area). Middle panels, triple labeling of GnRH (gray), Wnt-1GFP (green) and Islet-1/2 (red). The green and red boxes in middle panels are shown at a higher magnification (right panels) at all three individual wavelengthes. Green box: GnRH neurons negative for Islet-1/2 but positive for Wnt1-GFP. Red box: GnRH neurons positive for Islet-1/2 but negative for Wnt1-GFP (white asterisk). FB: forebrain, OE, olfactory epithelium; RE, respiratory epithelium; Scale bar, $10 \mu \mathrm{m}$. Clusters of $\mathrm{GnRH}$ cells, as seen in upper middle panel on right edge of photomicrograph were omitted from analysis due to inability to discern single cells. 
Total GnRH neuron numbers counted at E11.5 and E12.5 were consistant with previous results (Wray et al., 1989a). Cell counting of E11.5 and E12.5 Islet-1/2/GnRH co-stained animals revealed that $\sim 16-23 \%$ of the $\mathrm{GnRH}$ neuronal population was Islet-1/2(-) (Figure 1I). These results contrast the recent findings in zebrafish where all GnRH cells in the olfactory placode were positive for Islet-1/2 (Aguillon et al., 2018).

The percentage of Islet-1/2(-) GnRH neurons (16\% in E11.5 and $23 \%$ in E12.5) was close to the percentage of $\mathrm{GnRH}$ subpopulation proposed to arise from NC progenitors $(\sim 30 \%$, Forni et al., 2011), using Wnt1-cre/Rosa-YFP mouse line as a NC linage tracer (Forni et al., 2011). To determine if the Islet-1/2 immunopositive and negative GnRH cells corresponded to the placodal ectodermally derived and neural crest-derived GnRH subpopulations, triple labeling was performed for GnRH, Islet$1 / 2$, and GFP in Wnt1-cre/Rosa-YFP animals at E11.5 and E12.5 (Figures 2, 3). The analysis of E11.5 and E12.5 embryo sections from this line indicated that the GnRH neurons derived from Wnt1 progenitors [i.e., YFP positive $(\mathrm{YFP}(+)$ ], was negative for Islet-1/2 expression in the VNO at E11.5 (Figure 2, green boxes). A similar $\mathrm{YFP}(+) /$ Islet-1/2(-) subpopulation was detected on the migratory tracts at E12.5 (Figure 3, green boxes). A second antibody against Islet-1/2 gave similar results in E12.5 mouse sections (Supplementary Figure S1).

In the VNO of two E11.5 triple-labeled animals, the number of $\mathrm{GnRH}(+)$, Wnt1-YFP(+) cells that coexpressed Islet-1/2 was quantified using two methods. For the first method, GnRH cells were identified, and then examined for Wnt1-YFP and Islet-1/2 coexpression. In the second method, Wnt1-YFP $(+)$ cells were identified, and then examined for GnRH and Islet-1/2 coexpression. Only cells with distinct nuclei were quantified (Table 1). Using the first method, $71 \mathrm{GnRH}(+)$ cells were detected; $54 / 71$ were $\mathrm{GnRH}(+) /$ Islet $(+)$ and $18 / 71$ were $\mathrm{GnRH}(+) / \mathrm{Wnt}(+)$. In latter group, $15 / 18$ were Islet-1/2(-), 3/71 appeared triple-labeled and 2 cells labeled for just GnRH. Using the second method, $81 \mathrm{Wnt1-YFP}(+)$ cells were identified. Out of those, $18 / 81$ were $\mathrm{GnRH}(+)$. Out of this population, 15 were Islet-1/2(-), and 3/18 appeared triple-labeled. The few triple-labeled cells identified in the first method $(3 / 71)$ are most likely false positives due to the compact cellular density in the E11.5 VNO and/or Wnt1-YFP(+) processes wrapping around GnRH neurons, since 30/33 GnRH(+)/Wnt1-YFP(+) cells were Islet-1/2(-).

Together, these data show that labeling for Islet-1/2 distinguishes two subpopulations of GnRH neurons in the early developing nasal placode. Although the majority of GnRH neurons were Islet-1/2(+), a subpopulation of $\mathrm{GnRH}$ cells were Islet-1/2 negative. Consistent with $\mathrm{GnRH}$ neurons in mouse arising from two different sources of progenitor cells, the GnRH neuronal subpopulation lacking Islet-1/2, expressed the Wnt1 promoter-driven CRE recombination of Rosa-YFP. Together, these data are consistent with a dual lineage of $\mathrm{GnRH}$ neuroendocrine cells in mice, one arising from olfactory placodal ectoderm and the other from NC, and indicates that Islet-1/2 is a developmental marker in cell fate determination in the $\mathrm{GnRH}$ neuroendocrine system.

\section{DISCUSSION AND SUMMARY}

GnRH neurons originate in the olfactory placode, and migrate from the VNO to the NFJ. Once GnRH neurons reach the
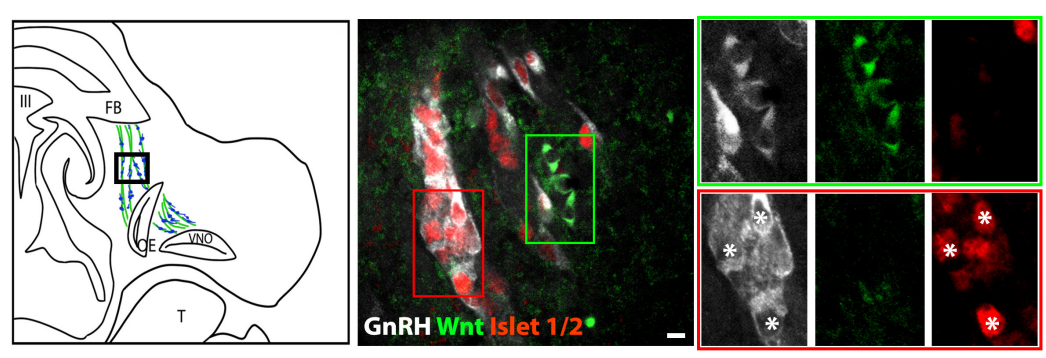

FIGURE 3 | Islet-1/2 staining identifies placodal ectodermally derived GnRH cells at E12.5. Left panel schematic of GnRH cells on migratory tracts (boxed area, green, sensory axons, blue, GnRH). Middle panel shows triple labeling of GnRH (gray), Wnt1-GFP (green) and Islet-1/2 (red). The green and red boxes indicate the two population of GnRH neurons negative and positive for Islet-1/2, respectively. Right panel shows magnified boxed areas in the middle panel at all three individual wavelengths. Green box: GnRH neurons negative for Islet-1/2, positive for Wnt1-GFP. Red box: GnRH neurons positive for Islet-1/2, negative for Wnt1-GFP. Asterisks, Islet-1/2 (+) GnRH cells. FB, forebrain; OE, olfactory epithelium; VNO, vomeronasal organ; III, third ventricle; T, tongue; Scale bar, $10 \mu \mathrm{m}$.

TABLE 1 | Quantification of GnRH, Wnt1-YFP and Islet-1/2 neurons in E11.5 VNO region.

\begin{tabular}{|c|c|c|c|c|}
\hline & GnRH + & GnRH + Wnt1 + & GnRH + IsI + & GnRH + Wnt1 + IsI- \\
\hline \multirow[t]{2}{*}{ Animal \#2 } & 43 & 9 & 35 & 7 \\
\hline & Wnt1 + & Wnt1 + GnRH + & Wnt1 + GnRH + IsI- & Wnt1 + IsI + \\
\hline Animal\#1 & 32 & 9 & 8 & 3 \\
\hline Animal\#2 & 49 & 9 & 7 & 4 \\
\hline
\end{tabular}


olfactory bulbs, they turn caudally, forming a continuum in the forebrain from the olfactory bulbs to the caudal hypothalamus. Independent of location, the majority of GnRH cells send their processes to the median eminence, where $\mathrm{GnRH}$ is secreted into the portal capillary system. When secretion of the $\mathrm{GnRH}$ peptide is pulsatile, gonadotropes of the anterior pituitary are activated and gonadal steroids released (Constantin, 2017; Shan and Wray, 2018). A dual origin for GnRH neuroendocrine cells has been proposed from studies in both zebrafish and mice (Whitlock et al., 2003; Forni et al., 2011). However, a recent study, using Islet-1/2, a LIM-homeodomain transcription factor that regulates cell fate, argued that all GnRH3 neurons in zebrafish (equivalent to $\mathrm{GnRH}$ neuroendocrine cells in mouse) were derived from placodal ectodermal progenitors. Using this same marker, this study finds that the majority of $\mathrm{GnRH}$ cells are indeed Islet$1 / 2(+)$. However, a subpopulation of Islet1/2(-) GnRH cells were found, and this population overlapped with the Wnt1 derived (NC) GnRH subpopulation. These results suggest that either (1) NC-derived GnRH cells differentiate earlier than PEderived GnRH cells and/or (2) different programs are used for cell specification in NC- vs. PE-derived GnRH cells. These data support a dual origin of $\mathrm{GnRH}$ neuroendocrine cells, one arising from olfactory placodal ectoderm and the other from $\mathrm{NC}$ progenitors. The functional significance of these two $\mathrm{GnRH}$ neuronal subpopulations still needs to be addressed.

\section{DATA AVAILABILITY STATEMENT}

All datasets generated for this study are included in the article/Supplementary Material.

\section{ETHICS STATEMENT}

All animal procedures were approved by the Animal Care and Use Committee and performed in accordance with the National

\section{REFERENCES}

Abraham, E., Palevitch, O., Gothilf, Y., and Zohar, Y. (2010). Targeted gonadotropin-releasing hormone-3 neuron ablation in zebrafish: effects on neurogenesis, neuronal migration, and reproduction. Endocrinology 151, 332340. doi: 10.1210/en.2009-0548

Aguillon, R., Batut, J., Subramanian, A., Madelaine, R., Dufourcq, P., Schilling, T. F., et al. (2018). Cell-type heterogeneity in the early zebrafish olfactory epithelium is generated from progenitors within preplacodal ectoderm. eLife 7:e32041. doi: 10.7554/eLife.32041

Avivi, C., and Goldstein, R. S. (1999). Differential expression of Islet-1 in neural crest-derived ganglia: Islet-1 + dorsal root ganglion cells are post-mitotic and Islet-1 + sympathetic ganglion cells are still cycling. Brain Res. Dev. Brain Res. 115, 89-92. doi: 10.1016/s0165-3806(99)00054-1

Barraud, P., Seferiadis, A. A., Tyson, L. D., Zwart, M. F., Szabo-Rogers, H. L., Ruhrberg, C., et al. (2010). Neural crest origin of olfactory ensheathing glia. Proc. Natl. Acad. Sci. U.S.A. 107, 21040-21045. doi: 10.1073/pnas.10122 48107

Constantin, S. (2011). Physiology of the gonadotrophin-releasing hormone $(\mathrm{GnRH})$ neurone: studies from embryonic GnRH neurones. J. Neuroendocrinol. 23, 542-553. doi: 10.1111/j.1365-2826.2011.02130.x
Institutes of Health, National Institute of Neurological Stroke and Disorders guidelines.

\section{AUTHOR CONTRIBUTIONS}

YS and SW designed the research, analyzed the data, and wrote the manuscript. YS and HS performed the experiments.

\section{FUNDING}

This work was supported by the Intramural Research Program of the National Institutes of Health, National Institute of Neurological Disorders and Stroke (ZIA NS002824-28).

\section{ACKNOWLEDGMENTS}

We thank Ms. Samantha Naya (a Newcomb Fellow, NIH) for cryosectioning embryonic section, Mr. Dakota Jacobs for WntCre/Rosa-YFP mice maintenance, and Dr. Stephanie Constantin for her valuable comments on the manuscript.

\section{SUPPLEMENTARY MATERIAL}

The Supplementary Material for this article can be found online at: https://www.frontiersin.org/articles/10.3389/fcell.2020.00035/ full\#supplementary-material

FIGURE S1 | Confirmation that Islet-1/2 expression delineates two populations of $\mathrm{GnRH}$ neurons. Changing the species of the primary antibodies used (chicken affinity purified against $\mathrm{GnRH}$ and rabbit polyclonal against Islet-1/2) gave similar results as those shown in Figure 1 (Polyclonal rabbit against $\mathrm{GnRH}$ and monoclonal mouse against Islet-1/2). Arrows indicate $\mathrm{GnRH}+($ green)/Islet-1/2 negative cells and asterisks indicate $\mathrm{GnRH}+/ /$ slet1/2 + (red) cells. Scale: $10 \mu \mathrm{m}$.
Constantin, S. (2017). Progress and challenges in the search for the mechanisms of pulsatile gonadotropin-releasing hormone secretion. Front. Endocrinol. 8:180. doi: 10.3389/fendo.2017.00180

Elshatory, Y., and Gan, L. (2008). The LIM-homeobox gene Islet-1 is required for the development of restricted forebrain cholinergic neurons. J. Neurosci. 28, 3291-3297. doi: 10.1523/JNEUROSCI.5730-07.2008

Ericson, J., Thor, S., Edlund, T., Jessell, T. M., and Yamada, T. (1992). Early stages of motor neuron differentiation revealed by expression of homeobox gene Islet-1. Science 256, 1555-1560. doi: 10.1126/science.1350865

Forni, P. E., Scuoppo, C., Imayoshi, I., Taulli, R., Dastru, W., Sala, V., et al. (2006). High levels of Cre expression in neuronal progenitors cause defects in brain development leading to microencephaly and hydrocephaly. J. Neurosci. 26, 9593-9602. doi: 10.1523/jneurosci.2815-06.2006

Forni, P. E., Taylor-Burds, C., Melvin, V. S., Williams, T., and Wray, S. (2011). Neural crest and ectodermal cells intermix in the nasal placode to give rise to GnRH-1 neurons, sensory neurons, and olfactory ensheathing cells. J. Neurosci. 31, 6915-6927. doi: 10.1523/JNEUROSCI.6087-10.2011

Forni, P. E., and Wray, S. (2012). Neural crest and olfactory system: new prospective. Mol. Neurobiol. 46, 349-360. doi: 10.1007/s12035-012-8286-5

Hobert, O., and Westphal, H. (2000). Functions of LIM-homeobox genes. Trends Genet. 16, 75-83. doi: 10.1016/s0168-9525(99)01883-1 
Hutchinson, S. A., and Eisen, J. S. (2006). Islet1 and Islet2 have equivalent abilities to promote motoneuron formation and to specify motoneuron subtype identity. Development 133, 2137-2147. doi: 10.1242/dev.02355

Kallmann, F. J., Schoenfeld, W. A., and Barrera, S. E. (1944). The genetic aspects of primary eunuchoidism. Am. J. Mental Defic. 48, 203-236.

Katoh, H., Shibata, S., Fukuda, K., Sato, M., Satoh, E., Nagoshi, N., et al. (2011). The dual origin of the peripheral olfactory system: placode and neural crest. Mol. Brain 4:34. doi: 10.1186/1756-6606-4-34

Kramer, P. R., Krishnamurthy, R., Mitchell, P. J., and Wray, S. (2000). Transcription factor activator protein-2 is required for continued luteinizing hormone-releasing hormone expression in the forebrain of developing mice. Endocrinology 141, 1823-1838. doi: 10.1210/endo.141.5.7452

Lee, B., Lee, S., Lee, S. K., and Lee, J. W. (2016). The LIM-homeobox transcription factor Isl1 plays crucial roles in the development of multiple arcuate nucleus neurons. Development 143, 3763-3773. doi: 10.1242/dev. 133967

Lee, H., Kim, M., Kim, N., Macfarlan, T., Pfaff, S. L., Mastick, G. S., et al. (2015). Slit and Semaphorin signaling governed by Islet transcription factors positions motor neuron somata within the neural tube. Exp. Neurol. 269, 17-27. doi: 10.1016/j.expneurol.2015.03.024

Lu, K. M., Evans, S. M., Hirano, S., and Liu, F. C. (2014). Dual role for Islet-1 in promoting striatonigral and repressing striatopallidal genetic programs to specify striatonigral cell identity. Proc. Natl. Acad. Sci. U.S.A. 111, E168-E177. doi: 10.1073 /pnas.1319138111

Metz, H., and Wray, S. (2010). Use of mutant mouse lines to investigate origin of gonadotropin-releasing hormone-1 neurons: lineage independent of the adenohypophysis. Endocrinology 151, 766-773. doi: 10.1210/en.2009-0875

Onuma, T. A., Ding, Y., Abraham, E., Zohar, Y., Ando, H., and Duan, H. (2011). Regulation of temporal and spatial organization of newborn GnRH neurons by IGF signaling in zebrafish. J. Neurosci. 31, 11814-11824. doi: 10.1523/ JNEUROSCI.6804-10.2011

Pfaff, S. L., Mendelsohn, M., Stewart, C. L., Edlund, T., and Jessell, T. M. (1996). Requirement for LIM homeobox gene Isl1 in motor neuron generation reveals a motor neuron-dependent step in interneuron differentiation. Cell 84, 309-320. doi: 10.1016/s0092-8674(00)80985-x

Schwanzel-Fukuda, M., and Pfaff, D. W. (1989). Origin of luteinizing hormonereleasing hormone neurons. Nature 338, 161-164. doi: 10.1038/338161a0

Shan, Y., and Wray, S. (2018). "Part II-2: prenatal development of GnRH neurons," in book: The GnRH Neurons and its Control, eds A. Herbison, and T. Plant (Hoboken, NJ: Wiley), 15-43.
Sun, Y., Dykes, I. M., Liang, X., Eng, S. R., Evans, S. M., and Turner, E. E. (2008). A central role for Islet1 in sensory neuron development linking sensory and spinal gene regulatory programs. Nat. Neurosci. 11, 1283-1293. doi: 10.1038/nn. 2209

Thaler, J. P., Koo, S. J., Kania, A., Lettieri, K., Andrews, S., Cox, C., et al. (2004). A postmitotic role for Isl-Class LIM homeodomain proteins in the assignment of visceral spinal motor neuron identity. Neuron 41, 337-350. doi: 10.1016/s08966273(04)00011-x

Whitlock, K. E., Wolf, C. D., and Boyce, M. L. (2003). Gonadotropin-releasing hormone $(\mathrm{GnRH})$ cells arise from cranial neural crest and adenohypophyseal regions of the neural plate in the zebrafish. Danio rerio. Dev. Biol. 257, 140-152. doi: 10.1016/s0012-1606(03)00039-3

Whittington, N. C., and Wray, S. (2017). Suppression of red blood cell autofluorescence for immunocytochemistry on fixed embryonic mouse tissue. Curr. Protoc. Neurosci. 81:2.28.1-2.28.12. doi: 10.1002/ cpns. 35

Wray, S. (2010). From nose to brain: development of gonadotrophin-releasing hormone-1 neurones. J. Neuroendocrinol. 22, 743-753. doi: 10.1111/j.13652826.2010.02034.x

Wray, S., Gahwiler, B. H., and Gainer, H. (1988). Slice cultures of LHRH neurons in the presence and absence of brainstem and pituitary. Peptides 9, 1151-1175. doi: 10.1016/0196-9781(88)90103-9

Wray, S., Grant, P., and Gainer, H. (1989a). Evidence that cells expressing luteinizing hormone-releasing hormone mRNA in the mouse are derived from progenitor cells in the olfactory placode. Proc. Natl. Acad. Sci. U.S.A. 86, 8132-8136. doi: 10.1073/pnas.86.20.8132

Wray, S., Nieburgs, A., and Elkabes, S. (1989b). Spatiotemporal cell expression of luteinizing hormone-releasing hormone in the prenatal mouse: evidence for an embryonic origin in the olfactory placode. Brain Res. Dev. Brain Res. 46, 309-318. doi: 10.1016/0165-3806(89)90295-2

Conflict of Interest: The authors declare that the research was conducted in the absence of any commercial or financial relationships that could be construed as a potential conflict of interest.

Copyright (C) 2020 Shan, Saadi and Wray. This is an open-access article distributed under the terms of the Creative Commons Attribution License (CC BY). The use, distribution or reproduction in other forums is permitted, provided the original author(s) and the copyright owner(s) are credited and that the original publication in this journal is cited, in accordance with accepted academic practice. No use, distribution or reproduction is permitted which does not comply with these terms. 